\title{
CdS Loaded an Iranian Clinoptilolite as a Heterogeneous Catalyst in Photodegradation of $p$-Aminophenol
}

\author{
Alireza Nezamzadeh-Ejhieh and Khodarahm Shirvani \\ Department of Chemistry, Islamic Azad University, Shahreza Branch, P.O. Box 311-86145, Shahreza, Isfahan, Iran \\ Correspondence should be addressed to Alireza Nezamzadeh-Ejhieh; arnezamzadeh@iaush.ac.ir
}

Received 16 June 2012; Accepted 22 September 2012

Academic Editor: Jacques Lalevee

Copyright (c) 2013 A. Nezamzadeh-Ejhieh and K. Shirvani. This is an open access article distributed under the Creative Commons Attribution License, which permits unrestricted use, distribution, and reproduction in any medium, provided the original work is properly cited.

\begin{abstract}
Natural clinoptilolite, zeolite CdS-incorporated was prepared by ion exchange and precipitation procedures and it was characterized by FT-IR, XRD, and thermal methods. The prepared composite was used as a catalyst in the photodegradation process of $p$-aminophenol in aqueous solution under UV irradiation. The effect of some key operating parameters such as catalyst dosage, temperature, the initial concentration of the pollutant, and initial $\mathrm{pH}$ of the solutions on the degradation process of the pollutant was studied. The primary objective was to determine the optimal conditions for each of the parameters. UV-vis spectrophotometric measurements were performed for the determination of degradation and mineralization extents. The optimal operation parameters were found as follows: $\mathrm{pH} 5,17.5 \mathrm{mg} \cdot \mathrm{L}^{-1}$ of catalyst loading, and $10 \mathrm{ppm}$ of dye concentration. The CdS particles out of zeolite framework do not show significant degradation efficiency. The degradation process obeyed first-order kinetics.
\end{abstract}

\section{Introduction}

Environment is the representative of physical components of the earth wherein man is the important factor influencing this environment. Among the different physical components, water is the most essential component of life. Total amount of water existing in the earth in the form of ground water, surface water, and so forth is $1.4 \times 10^{9} \mathrm{~km}^{3}$ approximately [1]. Mankind is constantly using this amount of water for different purposes including commercial and domestic uses. Due to natural calamities or some anthropogenic activities like inordinate population growth, fast industrialization, rapid urbanization, and modified agricultural operations, environmental pollution occurs, which has adverse effects on all forms of life. As water is one of the fundamental requirements of life, addition of any natural or artificial foreign matter from various sources such as industrial effluents, agricultural runoff, and chemical spills contaminates the water [2]. These effluents include several nonbiodegradable, toxic organic substances like pesticides, herbicides, dyes, and so forth. These substances are highly toxic, stable to natural decomposition, and are persistent to the environment [3]. $p$-aminophenol (PAP) is a commercially important intermediate for the manufacture of analgesic and antipyretic drugs [4]. It is also used as a developer in photography under trade names Activol and Azol and in chemical dye industries [5]. As a result, large amounts of PAP may enter the environment as a pollutant. This compound is very harmful for human body due to its structural similarity to aniline and phenol. $p$-aminophenol readily autoxidizes in solution and the rate increases with the $\mathrm{pH}$. It is in redox equilibrium with quinimine under aerobic conditions, and its potential is close to that of the quinhydrone system [6]. There may be cases in real life when rapid on-site determination of $p$-aminophenol is of vital importance, such as indirect detection of organophosphorus nerve agents and pesticides by measuring inhibition of acetylcholine esterase-catalyzed hydrolysis of $p$-aminophenyl acetate to PAP [7] or fast urinary screening and antidote administration for paracetamol which may cause lethal hepatic necrosis and renal failure at high doses [8]. Although a maximum contaminant level goal (MCLG) set by US-EPA for drinking water does not exist for $p$-aminophenol, acetaminophen (the pain-relieving drug which yields PAP upon hydrolysis) was one of the most 
frequently encountered organic pollutant in 127 surface water samples, found in the $1-100 \mathrm{ng} \mathrm{L}^{-1}$ range, analyzed by Minnesota Ground Water Association [9]. Decomposition of these effluents has therefore acquired increasing attention.

Recently, advanced oxidation processes (AOP) have been widely investigated of which heterogeneous photocatalysis has become the most popular. Photocatalytic systems are mainly based on semiconductor metal oxides since these solids are extremely robust materials and do not become self-degraded $[10,11]$. Most studies related to photocatalytic degradation of organic pollutants have been carried out using suspensions of powdered $\mathrm{TiO}_{2}$ in the treated solution [12]. However, from a practical point of view, separation of photocatalyst from the reaction mixture might cause some difficulties. Another disadvantage is an increase in the overall capital and running costs of the plant. Therefore, attempts to immobilize the catalyst on different supports have been made [13-15].

Heterogeneous photocatalysis is a branch of AOP where a semiconductor catalyst under UV irradiation is highly successful in the mineralization of pollutants. In this method, - OH radicals are generated under UV irradiation of an aqueous solution which plays a major role in the degradation or decolorization of pollutants. On the other hand, redox reactions take place on the surface of the semiconductor/solution interface upon irradiation of semiconductor particles with proper energy (wavelength) higher than the band gap of the catalyst. Due to absorption of proper energy/photons, the electron-hole pairs will produce on the surface of the catalyst which can degrade different organic compounds in an aqueous solution. The oxidizing radicals formed upon reaction of holes with water could attack pollutant molecule and disintegrate it into $\mathrm{CO}_{2}$ and $\mathrm{H}_{2} \mathrm{O}$ molecules which are nontoxic [13-15].

Zeolites are crystalline aluminosilicates with cavities, whose sizes can vary in the range from one to several tens of nanometers. It depends on the type of aluminosilicates framework, $\mathrm{Si} / \mathrm{Al}$ ratio, and origin of ion exchange cations, which stabilize negative charge of framework, and so forth [16]. Zeolites modified with transition metal ions have received increasing attention as promising catalysts for a variety of important reactions [17]. Zeolites can serve as hosts to activate transition metal ions, offering a unique ligand system with multiple types of coordination for cations. In addition, the restricted pore size of zeolites could limit the growth or sintering of the nanoparticles of the cation even at high temperatures [18].

Lewis acid sites are widely used in homogeneous catalysis to promote the reaction of organic substrate with oxidants. In the research area of green chemistry, development of new solid Lewis acids, active and selective for catalytic oxidation, is crucial especially in using environmentally benign oxidants. A significant step toward this goal is to identify the nature of Lewis acid sites, at the atomic level, existing in zeolites. Lewis acid sites can be attributed to extra framework aluminum species (EFAL) of octahedral or tetrahedral aluminum as well as tricoordinated $\mathrm{Al}$, partially dislodged in the framework. Zeolites are three-dimensional aluminosilicates containing exchangeable cations that act as Lewis acid sites. The framework oxygen atoms of alkali exchanged zeolites bear partial negative charge and behave as Lewis base [19].

Natural zeolites are extensively used in environmental processes and most applications of them are focused on the field of wastewater purification. There are many reasons for this: good selectivity for many toxic cations; limited effects for the lack of constancy of zeolite content in zeoliterich rock. Clinoptilolite $(\mathrm{CP})$ is the most abundant zeolite in nature, which is isostructural with heulandite and is the alkali-rich and silica-rich member of the heulandites group with a representative unit cell composition of $(\mathrm{Na}, \mathrm{K})_{6}\left(\mathrm{Al}_{6} \mathrm{Si}_{30} \mathrm{O}_{72}\right) \cdot 20 \mathrm{H}_{2} \mathrm{O}$. It is one of the most abundant zeolites and has a monoclinic framework consisting of a tenmembered ring $(7.5 \times 3.1 \AA)$ and two eight membered rings $(4.6 \times 3.6 \AA, 4.7 \times 2.8 \AA)$ [19]. It is defined as a member of the heulandite family with $\mathrm{Si} / \mathrm{Al}>4$. Clinoptilolite zeolite which was used in this paper has a $\mathrm{SiO}_{2} / \mathrm{AlO}_{2}$ ratio of 4.84 which has a good agreement with the literature $[16,19]$. The surface characteristics of the used clinoptilolite have been reported in our previous work [20].

CdS is a well-known semiconductor with a band gap of $2.42 \mathrm{eV}$ and its valence electron can be easily evoked to conduction band when the wavelength of evoking light is less than or equal to $495 \mathrm{~nm}[21,22]$. CdS semiconductor nanoparticles as photocatalyst have attracted intense interest to treat dyes wastewater due to their unique photochemical and photophysical properties in recent years [23, 24]. Mechanistically, CdS photocatalyst is first evoked by relevant light and subsequently initiates the photodegradation of contaminants. The physical properties of CdS nanoclusters encapsulated in zeolites $\mathrm{Y}, \mathrm{X}$, and A (especially in zeolite $\mathrm{Y}$ ) have been reported [25]. The CdS loading caused several CdS states of aggregation in the zeolite crystalline. For example in low loading ( $\leq 5 \mathrm{wt} \%)$, CdS forms $(\mathrm{CdS}, \mathrm{O})_{4}$ cubes clusters located within the sodalite cages [25]. For CdS loading higher than $5 \mathrm{wt} \%$, the clusters fill a higher number of sodalite cages, tending to occupy adjacent sodalite cages and beginning to interact with each other through the interconnecting channels. In this case, the CdS state of aggregation is called supercluster. At higher loading, CdS grows outside of zeolite cages as polycrystalline aggregates with the properties of $\mathrm{CdS}$ bulk semiconductor. The state of aggregation of CdS in zeolite hosts is directly manifested in the optical absorption spectra. CdS clusters in zeolite $\mathrm{Y}$ produce an absorption peak at about $280 \mathrm{~nm}$, which is strongly shifted to higher energy compared to the fundamental CdS absorption edge around $500 \mathrm{~nm}$. The cluster interaction in CdS superclusters shifts the absorption peak to $350 \mathrm{~nm}$. The transition from cluster to supercluster is not continuous but rather abrupt indicating a percolative process [25].

The research subject of our group is studying the effect of various transition metal sulfides incorporated in zeolites toward photodegradation of pollutants. To our knowledge, preparation of these sulfides, with respect to their oxides, is easy due to the large formation constant of these compounds. Low leaching of these sulfide compounds, due to low solubility, is another advantage. Sulfides of many transition metals 
show electronic and optical properties such as semiconductivity and photoconductivity. Thus, the synthesis of the $3 \mathrm{~d}$ transition metal sulfides has attracted great interests for several decades. In this work, CdS formed inside the channels of clinoptilolite zeolite, by precipitation after ion exchange process. The obtained composite was applied as photocatalyst in the degradation of PAP. The effects of different parameters such as catalyst amount, initial concentration of the pollutant, initial $\mathrm{pH}$, and temperature of the solution were investigated on the degradation efficiency of the pollutant.

\section{Experimental}

2.1. Chemicals. Natural clinoptilolite tuffs were obtained from Semnan region in the north-east of Iran. $p$-aminophenol $\left(\mathrm{C}_{6} \mathrm{H}_{7} \mathrm{NO}\right)$ and other chemicals with analytical grade were obtained from Merck. Distilled water was used throughout the experiments. The $\mathrm{pH}$ of solutions was adjusted with sodium hydroxide or hydrochloric acid solution as appropriate.

2.2. Purification of Zeolite Sample. Natural clinoptilolite tuffs were mechanically pretreated, by crushing in an agate mortar and sieving in analytical sieves, for the separation of the $<100 \mu \mathrm{m}$ particle-size fractions. To remove water soluble impurities, the obtained powder was refluxed at $70^{\circ} \mathrm{C}$ for 3 days. After filtration and washing, the purified material was stored in a desiccator over saturated sodium chloride solution for 2 weeks, in order to reach a constant water content.

2.3. Catalyst Preparation. Stock solution of Cd(II) was prepared in water using the analytical reagent grade of its nitrate salt. For ion exchange experiment, $8 \mathrm{~g}$ of purified clinoptilolite powder was added to $100 \mathrm{~mL}$ of $0.1 \mathrm{M}$ abovementioned cation solution and stirred at room temperature for $12 \mathrm{~h}$. The procedure was repeated again to reach a more complete ion exchange. The sample was filtered off, washed with water, and dried at $110^{\circ} \mathrm{C}$. The color of the obtained sample was changed after ion exchange process. Finally, sulfurizing of the ion exchanged form was carried out with $0.1 \mathrm{M} \mathrm{Na}_{2} \mathrm{~S}$ solution. To make the reaction with $\mathrm{S}^{2-}$ ions, $2 \mathrm{~g}$ of exchanged sample was added to $100 \mathrm{~mL}$ of $0.1 \mathrm{M}$ solution of $\mathrm{Na}_{2} \mathrm{~S}$ at a fixed temperature and stirred for $30 \mathrm{~min}$. The obtained sample was washed with water and collected by filtration to remove the sulfide ions. The obtained sample was fine powder with a change in color. The sample was kept at ambient conditions and its color did not changed during with time, indicating the high stability of the sample. To investigate the effect of cadmium sulfide loading on degradation process, three catalysts were prepared by ion exchange of zeolite in $0.01,0.1$ and $0.2 \mathrm{M}$ of $\mathrm{Cd}^{2+}$ solutions. Sulfurization of the samples was carried out according to the above-mentioned method.

2.4. Catalyst Characterization. The X-ray diffraction pattern of clinoptilolite was performed using a Bruker diffractometer (D8 Advance) with Ni-filtered copper radiation
$\left(K_{\alpha}=1.5406 \AA\right)$ and $2 \theta$ range of $10-80^{\circ}$. FT-IR spectra of the samples, on $\mathrm{KBr}$ pellets, were recorded with a Nicolet single beam FT-IR (Impact 400D) spectrometer in the range of $400-4000 \mathrm{~cm}^{-1}$ at room temperature. Differential scanning calorimetry (DSC) and DTG thermograms were performed for the samples $(6 \mathrm{mg})$ using Model Setaram STA units in the range of $50-700^{\circ} \mathrm{C}$ with temperature rise of $10^{\circ} \mathrm{C} \cdot \mathrm{min}^{-1}$.

2.5. The Catalytic Activity. Photodegradation experiments were performed with a photocatalytic reactor system. The bench-scale system is a cylindrical Pyrex-glass cell with $1.0 \mathrm{~L}$ capacity, $10 \mathrm{~cm}$ inside diameter, and $15 \mathrm{~cm}$ height. Irradiation experiments were performed using medium pressure $\mathrm{Hg}$ lamp ( $75 \mathrm{~W}, \lambda=250-420 \mathrm{~nm}$ ), then it was placed in a $5 \mathrm{~cm}$ diameter quartz tube with one end tightly sealed by a Tefloon stopper. The lamp and the tube were immersed in the photoreactor cell with a light path of $3.0 \mathrm{~cm}$. To prevent CdS photocorrosion, for a typical photocatalytic experiment, catalyst should be added to an aqueous solution containing $0.1 \mathrm{M} \mathrm{Na}_{2} \mathrm{SO}_{3}$ and $0.1 \mathrm{M} \mathrm{Na}_{2} \mathrm{~S}$ [26]. A magnetic stirrer was used continuously to guarantee good mixing of the solution. Unless otherwise stated, the reaction was carried out at room temperature under the conditions of $17.5 \mathrm{mg} \cdot \mathrm{L}^{-1}$ of the solid catalyst in a solution of $10 \mathrm{ppm}$ PAP, and the $\mathrm{pH}$ of the solution was initially about 7. Generally, $\mathrm{HCl}(1 \mathrm{M})$ and $\mathrm{NaOH}(1 \mathrm{M})$ were used to adjust the $\mathrm{pH}$ value in the beginning of all experiments including the effect of $\mathrm{pH}$ study. The degradation of PAP pollutant was analyzed by UVvis spectrophotometer (Carry $100 \mathrm{Scan}$ ). The degradation was determined at the wavelength of maximum absorption $(296 \mathrm{~nm})$ of the PAP. Degradation efficiency was determined using absorbance of solutions before and after photodegradation experiments. Calibration plots based on Beer's low were established with the absorbance and the concentration of the pollutant. The degradation of PAP pollutant was fitted with first-order kinetics $\left[\ln \left(C / C^{\circ}\right)=-k t\right]$ (where $C^{\circ}$ and $C$ are the initial and final pollutant concentration at time $t$, respectively, and $\left(k, \mathrm{~h}^{-1}\right)$ is the reaction rate constant). The rate constant, $k$, was calculated from the slopes of the straightline portion of the plots $\left[\ln \left(C / C^{\circ}\right)\right.$ versus time]. To determine the surface adsorption amount, control experiments were carried out in the dark condition and in parallel in each case at the presence of catalyst on the degradation of PAP.

\section{Result and Discussions}

\subsection{Characterization of the Samples}

3.1.1. Chemical Analysis of Raw Material. The chemical composition of purified natural clinoptilolite, which was determined by the Maxwell method [27], is presented in Table 1. The $\mathrm{SiO}_{2} / \mathrm{AlO}_{2}$ ratio of clinoptilolite is 4.84, and this value is within the ranges which have reported by Breck [16]. There is good agreement between the obtained results and the literature, [18], showing that the used zeolite is clinoptilolite.

3.1.2. XRD Patterns. The X-ray diffraction (XRD) patterns of raw purified clinoptilolite and CdS-CP zeolite samples are 
TABLE 1: Chemical compositions of natural clinoptilolite zeolite.

\begin{tabular}{lc}
\hline Oxide components & Weight $\%$ \\
\hline $\mathrm{SiO}_{2}$ & $67.1 \pm 0.20$ \\
$\mathrm{Al}_{2} \mathrm{O}_{3}$ & $11.7 \pm 0.05$ \\
$\mathrm{Fe}_{2} \mathrm{O}_{3}$ & $1.51 \pm 0.01$ \\
$\mathrm{CaO}$ & $2.64 \pm 0.03$ \\
$\mathrm{MgO}$ & $0.74 \pm 0.01$ \\
$\mathrm{Na}_{2} \mathrm{O}$ & $1.84 \pm 0.02$ \\
$\mathrm{~K}_{2} \mathrm{O}$ & $1.93 \pm 0.03$ \\
$\mathrm{TiO}_{2}$ & $0.21 \pm 0.02$ \\
$\mathrm{~L}_{2} . \mathrm{I}^{*}$ & $12.3 \pm 0.07$ \\
$\mathrm{SiO}_{2} / \mathrm{AlO}_{2}$ & 4.86 \\
\hline
\end{tabular}

Loss on ignition.

shown in Figure 1. The parent clinoptilolite showed a pattern similar to the crystalline structure reported in the X-ray data file (JCPDS no. 39-1383) and those of [28]. This analysis shows that the product has a typical zeolite clinoptilolite structure as major component. The powder XRD results of the $\mathrm{CP}$, and the host-guest composite material, CdS-CP show similar diffraction peaks indicative of clinoptilolite. This indicates that the zeolite structure does not change due to the incorporation of CdS particles. But, some differences, such as the broadening of the diffraction peaks, increasing or decreasing of some peaks intensities as well as the shift of the peak position to the slightly lower angles can be observed in the spectra. In fact, the intensities of the peaks in the hostguest composite material are decreased with respect to those of clinoptilolite. This decrease of the peaks intensities can be related to the presence or incorporation of semiconductor inside the matrix structure. These peaks are located approximately at $2 \theta$ equal to $10^{\circ}, 11.5^{\circ}, 13.5^{\circ}, 16.8^{\circ}, 17.2^{\circ}, 19.0^{\circ}$, $22.1^{\circ}, 25.1^{\circ}, 26.0^{\circ}, 26.1^{\circ}, 30.2^{\circ}$, and $32.5^{\circ}$. These changes in the relative intensities of the clinoptilolite peaks were found in XRD pattern after ion exchange and sulfurization treatments, and took place in natural clinoptilolite, which has already been demonstrated by Kida et al. [29] and Sathish et al. [30]. The pure CdS powder has characteristics XRD lines in 26.5, 32.5, 36.5, 46, and 54 degrees (JCPDS no. 41-1049). In our results, the used clinoptilolite has also characteristic lines located in CdS lines and overlay with each other. Due to this and also due to the low loading of CdS in CdS$\mathrm{CP}$ sample, CdS XRD lines do not appear separately. To confirm the presence of CdS in the CdS-CP sample, the sample was appropriately digested in HF and XRD pattern of the extracted CdS was prepared (inset of Figure 1).

By analysis of the $\beta$, excess of width line of the diffraction peak in radians and $\theta$, the Bragg angle in degrees and using the Debye-Scherrer formula, $d=0.9 \lambda / \beta \cos \theta$, where $d$ is the average diameter of the crystal and $\lambda$ the wavelength of X-ray, we determined the average size of CP and CdS-CP samples to be 2.7 and $2.3 \mu \mathrm{m}$, respectively. The average diameter of the $\mathrm{CdS}$ incorporated in zeolite was about $7.3 \mathrm{~nm}$.

3.1.3. FT-IR Spectra. FT-IR lattice vibration spectra were used to investigate the influence of cadmium on the clinoptilolite framework. Representative spectra of the $\mathrm{CP}$,

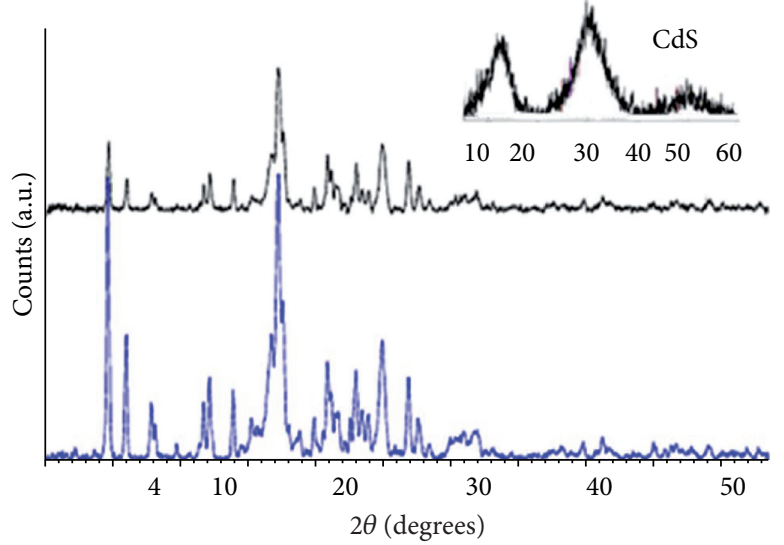

FIGURE 1: X-ray diffraction patterns of parent zeolite CP (a) and CdS-CP (b) in $2 \theta$ range of $5-60^{\circ}$, (inset: XRD pattern of CdSincorporated zeolite).

Cd-CP and CdS-CP, samples in the range of $400-4000 \mathrm{~cm}^{-1}$ are shown in Figure 2. The main peaks at 474, 615, 790, and $1085 \mathrm{~cm}^{-1}$ have the general assignment given by Flanigen et al. [31] for the vibrational modes of the zeolite. The $1085 \mathrm{~cm}^{-1}$ band is due to the asymmetric stretching vibration modes of internal T-O bonds in $\mathrm{TO}_{4}(\mathrm{~T}=\mathrm{Al}$ or $\mathrm{Si})$ tetrahedra $[18,31]$. The 790 and $474 \mathrm{~cm}^{-1}$ bands are assigned to the stretching vibration modes of $\mathrm{O}-\mathrm{T}-\mathrm{O}$ groups and the bending vibration modes of $\mathrm{T}-\mathrm{O}$ bonds, respectively $[18,31]$. It has been reported that the length of $\mathrm{Al}-\mathrm{O}$ bond is longer than that of $\mathrm{Si}-\mathrm{O}$ bond and that the substitution of tetrahedral $\mathrm{Al}$ for $\mathrm{Si}$ in aluminosilicate frameworks induces a lower wavenumber shift of the stretching vibration $\mathrm{T}-\mathrm{O}$ band [31]. Bonding of divalent cations to the framework oxygen atoms causes local deformation of the zeolite framework, which may be detected in T-O-T vibration changes [32]. The addition of $\mathrm{Cd}^{2+}$ caused local deformation or shift of the vibrational band at 464, 611, 797, and $1058 \mathrm{~cm}^{-1}$ (Figure 2(b)). The symmetric stretching band of T-O-T vibrations at $790 \mathrm{~cm}^{-1}$ in clinoptilolite was shifted into $797 \mathrm{~cm}^{-1}$ in the CdS-CP. The deformation of the band at 464 and $797 \mathrm{~cm}^{-1}$ and the bands which located between 611 and $797 \mathrm{~cm}^{-1}$ reflects the preferential sitting of $\mathrm{Cd}^{2+}$ ions as coordinated bonding to the framework oxygen atoms. Similar result was obtained in investigation of the effect of $\mathrm{Cd}^{2+}$ ions in cationic sites of ferrierite [33]. Moreover, the absorption band at $1058 \mathrm{~cm}^{-1}$ confirmed the location of cadmium as coordinated framework $\mathrm{Cd}^{2+}$ ions [34]. Comparison of the spectra in Figure 2 shows the slightly shift of $464,611,792$, and $1058 \mathrm{~cm}^{-1}$ (Figure 2(b)) to $473,610,796$ and $1074 \mathrm{~cm}^{-1}$ (Figure 2(c)), respectively. These changes can be related to the conversion of $\mathrm{Cd}^{2+}$ to $\mathrm{CdS}$ after the sulfurizing process.

3.1.4. Thermal Analysis. The DTG and DSC curves of the CP and CdS-CP samples are shown in Figure 3. The DTG results for clinoptilolite are similar to the literature [21]. According to DTG curves, water is lost at 117 and $140^{\circ} \mathrm{C}$ in the CP 


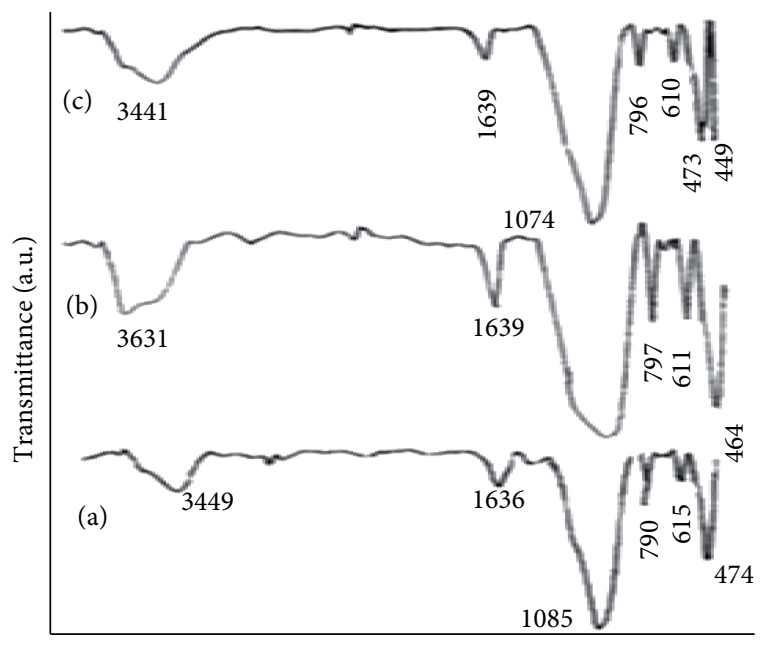

Wavenumber $\left(\mathrm{cm}^{-1}\right)$

Figure 2: FT-IR spectra of raw CP (a), $\mathrm{Cd}^{2+}-\mathrm{CP}(\mathrm{b})$, and CdS-CP samples (c).

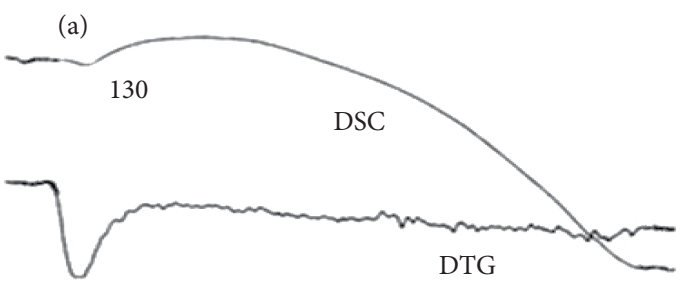

117

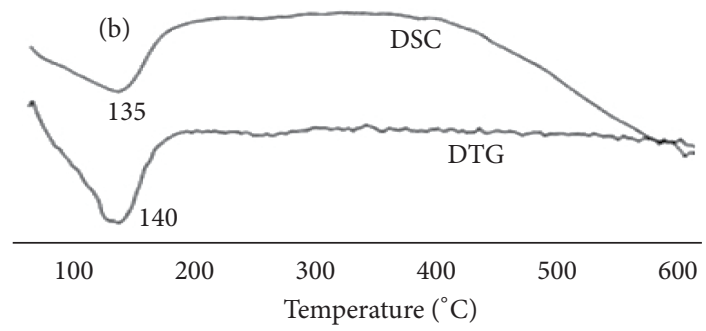

FIGURE 3: Thermal analysis curves spectra of CP zeolite (a) and CdSCP samples (b).

and CdS-CP samples, respectively. There are three shoulders in the case of CdS-CP (Figure 3(b)). These observations are in accordance with the presence of more water sites in the CdS-CP structure. The presence of different exchangeable cations in zeolites leads to some changes in the temperature correspond to zeolitic water elimination, which is held in a few stages [35]. The shift in DTG peaks to $140^{\circ} \mathrm{C}$ for CdS$\mathrm{CP}$, also showing difficulty of water loss. Authors suggest that these changes in the DTG curves indicate change in hydration extent of the structure due to precipitation of $\mathrm{Cd}^{2+}$ as $\mathrm{CdS}$. The DTG results were confirmed by the data from the DSC curves which show an endothermic peak at 130 and $135^{\circ} \mathrm{C}$ for zeolite CP and CdS-CP, respectively. Sulfur compounds

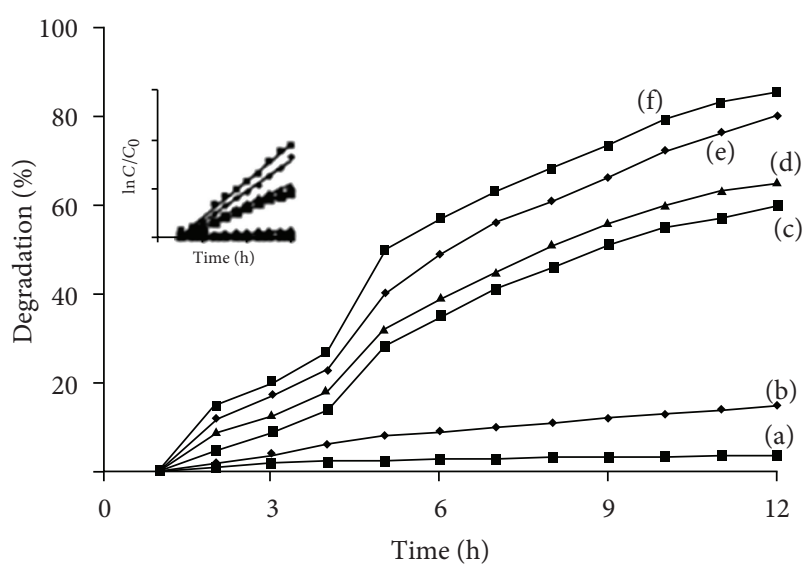
(a) PAP
(d) $25 \mathrm{mg} / \mathrm{L}$
(b) PAP + UV
(e) $12.5 \mathrm{mg} / \mathrm{L}$
(c) $75 \mathrm{mg} / \mathrm{L}$
(f) $17.5 \mathrm{mg} / \mathrm{L}$

Figure 4: Effect of CdS-CP dosage on the degradation efficiency; initial PAP concentration, $25 \mathrm{ppm}$; initial $\mathrm{pH}, 7$.

must be evolved at $450-550^{\circ} \mathrm{C}$ [36]. Thermal curves of CdS$\mathrm{CP}$ show no evolvement of any substances in this region. The obtained result shows the high stability of CdS in the surface and cavity of the zeolite. The weight loss percent of zeolite CP and CdS-CP samples was approximately obtained from DTG curves at about 11.5 and $12.9 \%$, respectively. The most essential loss of mass is observed at $50-200^{\circ} \mathrm{C}$ because of desorption of intact water and associatively desorption of hydroxy species.

\subsection{Catalytic Activity of CdS/CP Zeolite}

3.2.1. Effect of CdS Loading. The influence of CdS loading of $\mathrm{CP}$ zeolite on PAP degradation was studied using the same above-mentioned experimental conditions using $12.5 \mathrm{mg} \cdot \mathrm{L}^{-1}$ of the CdS-CP catalyst. Three catalysts were prepared by ion exchange of zeolite $\mathrm{CP}$ in $0.01,0.1$, and $0.2 \mathrm{M}$ of $\mathrm{Cd}^{2+}$ aqueous solutions. According to atomic absorption results of cadmium determination, their CdS contents were 4.5, 15.0 , and $17.2 \%$, respectively. Many authors reported that the kinetic behavior of the photocatalytic reactions obeys the first-order reaction [37]. In order to confirm the speculation, $\ln \left(C_{0} / C\right)$ was plotted as a function of the irradiation time. The calculated results indicated that the first-order model gives better fit. The rate constant values, $k\left(\mathrm{~h}^{-1}\right)$, are calculated from the straight-line portion of the first-order plots as a function of the catalyst loading and are 0.0012, 0.096, and $0.101 \mathrm{~h}^{-1}$ for CdS loading of $4.5,15.0$, and $17.2 \%$, respectively. As the results show, there is no significant difference between the degradation efficiency of the catalyst containing 15.0 and $17.2 \% \mathrm{CdS}$. Hence, the optimum value of $15.0 \% \mathrm{CdS}$ was used in later investigations.

3.2.2. Effect of Dosage of Catalyst. The effect of catalyst loading on the rate of the degradation extent of a $25 \mathrm{ppm}$ PAP solution was investigated keeping all other experimental 


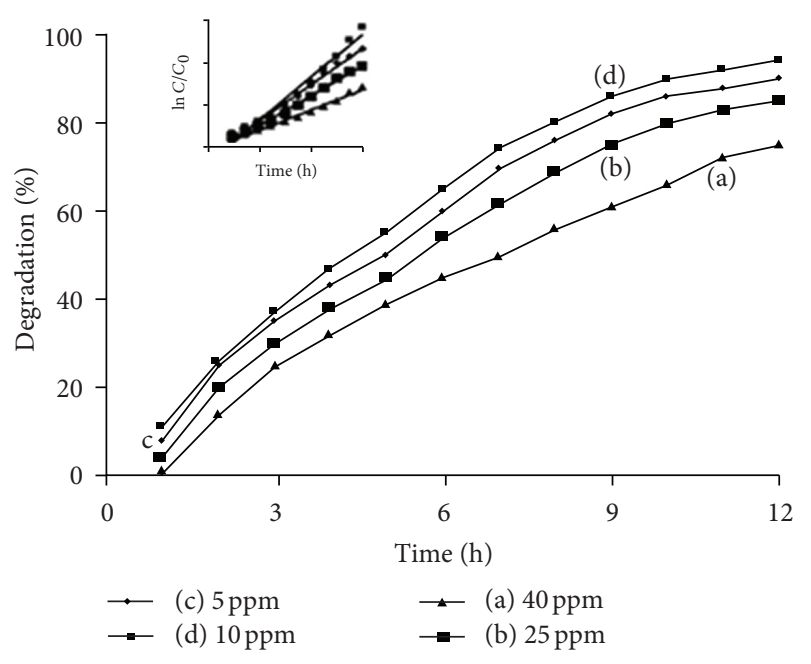

FIGURE 5: Effect of the initial PAP concentration on the degradation efficiency; $17.5 \mathrm{mg} \cdot \mathrm{L}^{-1}$ of catalyst; initial solution $\mathrm{pH}, 7$.

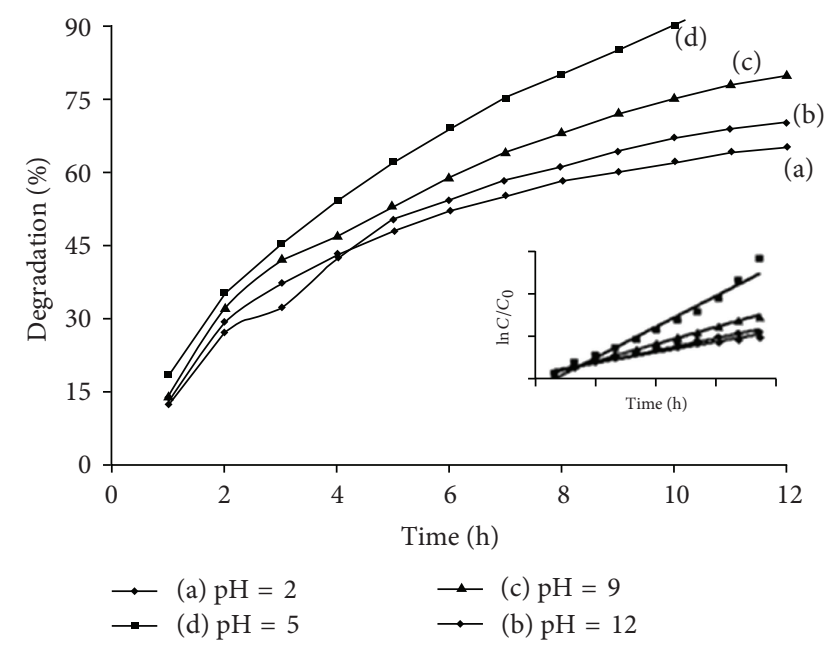

FIGURE 6: Influence of solution $\mathrm{pH}$ on the degradation of PAP; $17.5 \mathrm{mg} \cdot \mathrm{L}^{-1}$ of catalyst; initial PAP concentration, $10 \mathrm{ppm}$.

parameters constant and the results are shown in Figure 4. There is a steady increase in the rate of the degradation up to $17.5 \mathrm{mg} \cdot \mathrm{L}^{-1}$ of the catalyst beyond which the rate decreases. The increase of the catalyst loading from 12.5 to $17.5 \mathrm{mg} \cdot \mathrm{L}^{-1}$ increases the degradation rate due to the increase in the catalyst surface area, which enhances absorption of photons. The decrease at higher loading beyond the optimum level of $17.5 \mathrm{mg} \cdot \mathrm{L}^{-1}$ is due to decrease in the light penetration and deactivation of activated molecules due to collision with the ground-state molecules [38]. So the overall number of the photons that can be reached to catalyst particles and the production of $\mathrm{OH}$ radicals are decreased with the loading of the catalyst. Further, at higher catalyst loading it is difficult to maintain the suspension homogeneous due to particles agglomeration which decreases the number of active sites [39]. In our previous work, the degradation of Eriochrome Black $\mathrm{T}$ was studied using Ni-zeolite $\mathrm{P}$ catalyst and the results showed that the degradation efficiency was decreased with increasing in the catalyst amount higher than $0.8 \mathrm{~g} \cdot \mathrm{L}^{-1}$ [40]. According to control experiment results, the surface adsorbed of PAP has $8.5 \%$ maximum value and this value was decreased from total degradation values in all degradation calculations.

In order to calculate $k$ values, $\ln \left(C_{0} / C\right)$ was plotted as a function of the irradiation time (inset of Figure 4 ). The rate constant values, $k\left(\mathrm{~h}^{-1}\right)$, are calculated from the straightline portion of the first-order plots as a function of the catalyst mass and listed in Table 2 . As the results show, maximum degradation (85\%) of PAP pollutant with a maximum rate constant $\left(0.1832 \mathrm{~h}^{-1}\right)$ was obtained in the presence of $17.5 \mathrm{mg} \cdot \mathrm{L}^{-1}$ of the catalyst. Therefore, $17.5 \mathrm{mg} \cdot \mathrm{L}^{-1}$ of the catalyst was used in the next studies.

3.2.3. Effect of the Initial PAP Concentration. The effect of the initial concentration of the PAP pollutant on photodegradation efficiency is shown in Figure 5. The photodegradation conversion of the PAP was decreased with increasing in the initial PAP concentration to more than $10 \mathrm{ppm}$ because, as the initial concentration of PAP was increased, more PAP molecules were adsorbed on the surface of the catalyst, and the generation of $\mathrm{OH}$ radicals at the catalyst surface was reduced since the active sites were occupied by PAP molecules. Moreover, increasing in the concentration of PAP caused the PAP molecules to absorb light. As a result, fewer photons could reach the photocatalyst surface and so, photodegradation efficiency was decreased $[40,41]$. This is also simplified in Table 2 where the degradation rate constants, $\left(k, \mathrm{~h}^{-1}\right)$, are listed as a function of initial concentration of pollutant. It is apparent that the rate of degradation is a quantitative of concentration dependence and the activity was increased with increasing in the concentration to $10 \mathrm{ppm}$.

3.2.4. Effect of $p H$. The effect of the $\mathrm{pH}$ on photodegradation efficiency versus time is shown in Figure 6. Inset of Figure 6 shows the plot of $\ln \left(C_{0} / C\right)$ versus time as a function of initial $\mathrm{pH}$ of the PAP solutions. The rate constant values $\left(k, \mathrm{~h}^{-1}\right)$ as a function of $\mathrm{pH}$ on the degradation process are presented in Table 2. It is clear that the degradation of the pollutant was increased with raising $\mathrm{pH}$. According to data of Table 2, it is apparent that the rate of degradation is $\mathrm{pH}$-dependent and the activity is increased with increasing in $\mathrm{pH}$. The decrease of the efficiency in the initial acidic and alkaline conditions can be also explained by considering the following parameters.

(i) In the initial acidic pHs, concomitant with acidification of the solution by $\mathrm{HCl}$, a high amount of $\mathrm{Cl}^{-}$anion is added to the solution. The anion $\mathrm{Cl}^{-}$ is able to react with hydroxyl radicals leading to inorganic radical ions and producing $\mathrm{ClO}^{-}$radicals. These inorganic radical anions show a much lower reactivity than ${ }^{\bullet} \mathrm{OH}$, so that they do not take part in the pollutant mineralization. There is also a drastic competition between the PAP pollutant and anions with respect to ${ }^{\circ} \mathrm{OH}[40,42]$. 
TABLE 2: Reaction rate constant of PAP degradation as a function of experimental parameters.

\begin{tabular}{lcc}
\hline Parameter & Value & $k \times 10^{3}\left(\mathrm{~h}^{-1}\right)$ \\
\hline & $0^{\mathrm{a}}$ & 2.2 \\
& $0^{\mathrm{b}}$ & 12.7 \\
Catalyst mass $\left(\mathrm{mg} \cdot \mathrm{L}^{-1}\right)$ & 12.5 & 152.7 \\
& 17.5 & 183.2 \\
& 25.0 & 104.2 \\
& 75.0 & 92.9 \\
\hline \multirow{3}{*}{$C_{\text {PAP }}(\mathrm{ppm})$} & 5.0 & 212.5 \\
& 10.0 & 254.5 \\
& 25.0 & 174.3 \\
$\mathrm{pH}$ & 40.0 & 121.6 \\
& 2.1 & 82.5 \\
& 5.1 & 250.0 \\
& 9.0 & 132.0 \\
Temperature $\left({ }^{\circ} \mathrm{C}\right)$ & 12.1 & 92.3 \\
\hline
\end{tabular}

a 25 ppm PAP under dark conditions and ${ }^{\mathrm{b}} 25$ ppm PAP under UV irradiation conditions.

(ii) At alkaline pHs, the amount of conjugate base of $\mathrm{H}_{2} \mathrm{O}_{2}$ increases $\left(\mathrm{HO}_{2}^{-\bullet}\right) . \mathrm{HO}_{2}^{-\bullet}$ has a higher crosssection $\left(240 \mathrm{~mol} \mathrm{~cm}^{-1}\right)$ than $\mathrm{H}_{2} \mathrm{O}_{2}\left(18.6 \mathrm{~mol} \mathrm{~cm}^{-1}\right)$ at $254 \mathrm{~nm}$, which favors the absorption of $\mathrm{UV}$ by $\mathrm{HO}_{2}^{-\bullet}$ and should normally increase the ${ }^{\circ} \mathrm{OH}$ production $\left(\mathrm{HO}_{2}{ }^{-\bullet}+\mathrm{H}^{+}+h v \rightarrow 2^{\bullet} \mathrm{OH}\right)$. But $\mathrm{HO}_{2}{ }^{-}$, the conjugate anion of $\mathrm{H}_{2} \mathrm{O}_{2}$, reacts with a nondissociated molecule of $\mathrm{H}_{2} \mathrm{O}_{2}\left(\mathrm{HO}_{2}^{-}+\mathrm{H}_{2} \mathrm{O}_{2} \rightarrow \mathrm{H}_{2} \mathrm{O}+\mathrm{O}_{2}\right.$ $+{ }^{\bullet} \mathrm{OH}^{-}$) which leads to oxygen and water, instead of hydroxyl radicals under UV irradiation. Therefore, the instantaneous concentration of ${ }^{\bullet} \mathrm{OH}$ is lower than expected [42]. Furthermore, the deactivation of ${ }^{\bullet} \mathrm{OH}$ is more important when $\mathrm{pH}$ of the solution is high. The reaction of ${ }^{\bullet} \mathrm{OH}$ with $\mathrm{HO}_{2}{ }^{-}$, which produces $\mathrm{H}_{2} \mathrm{O}$ and $\mathrm{O}_{2}{ }^{\bullet}$, is approximately 100 times faster than its reaction with $\mathrm{H}_{2} \mathrm{O}_{2}$ (which produces $\mathrm{H}_{2} \mathrm{O}, \mathrm{O}_{2}$, and $\mathrm{OH}^{-}$). The reactivity of $\mathrm{O}_{2}{ }^{\bullet}$ and $\mathrm{HO}_{2}{ }^{\bullet}$ with organic pollutants is very low compared to that of $\mathrm{H}_{2} \mathrm{O}_{2}$ [43].

(iii) The self-decomposition rate of hydrogen peroxide (that yields $\mathrm{H}_{2} \mathrm{O}$ and $\mathrm{O}_{2}$ ) strongly depends on $\mathrm{pH}$. In practice, $\mathrm{H}_{2} \mathrm{O}_{2}$ is supplied in slightly acid condition $(\mathrm{pH} 5)$ for the sake of its high self-decomposition rate at high $\mathrm{pHs}[42]$.

3.2.5. Effect of Temperature. To study the effect of temperature, the same conditions were repeated. However, a temperature range of $25-70^{\circ} \mathrm{C}$ was investigated and the results are shown in Figure 7. The rise in the temperature shows that it is effective at the initial stages of the process. As the results show, increasing in temperature up to $45^{\circ} \mathrm{C}$, causes an increase in the degradation efficiency and after that

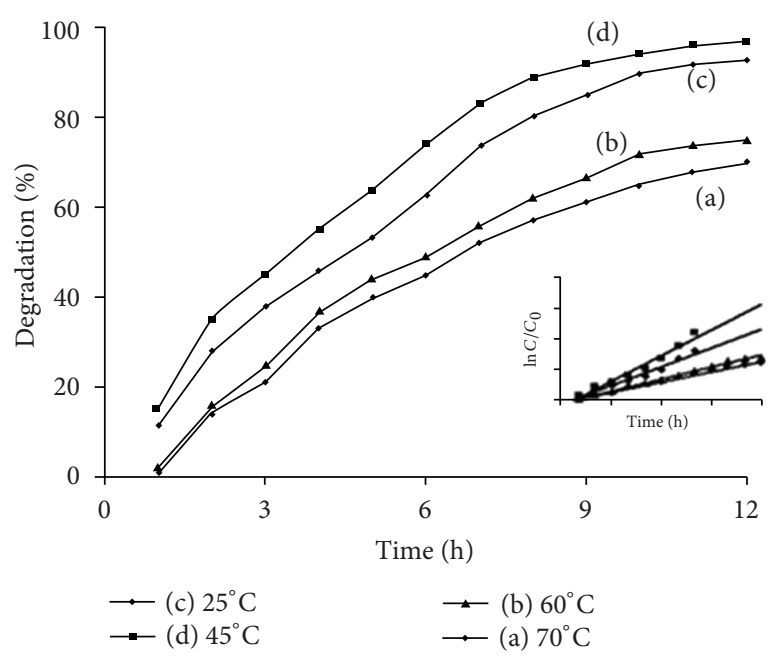

FIGURE 7: Effect of the reaction temperature on the degradation efficiency; $17.5 \mathrm{mg} \cdot \mathrm{L}^{-1}$ of catalyst; initial solution $\mathrm{pH}$, 5 ; initial PAP concentration, $10 \mathrm{ppm}$.

a decrease. Saien and Soleymani reported that an increase in temperature helps the reaction to compete more effectively with $e_{\mathrm{CB}}^{-}-h_{\mathrm{VB}}^{+}$recombination [44]. Previous work has also proved the effect of the temperature on Fenton and Fentonlike oxidation studies and found that the process efficiency was improved with increasing in temperature [45]. The rate constant values $\left(k, \mathrm{~h}^{-1}\right)$ as a function of temperature on the pollutant degradation were calculated from the linear segment of the plot of $\ln \left(C / C_{0}\right)$ versus time (inset of Figure 7) and the obtained results are presented in Table 2. Generally, increasing in the temperature enhances recombination of charge carriers and desorption process of adsorbed reactant species, resulting in decrease of the photocatalytic activity. This is in conformity with Arrhenius equation, for which the apparent first-order rate constant, $k_{\text {app }}$, should increase linearly with $\exp (-1 / T)[46]$. Hence, a decrease in degradation efficiency was observed in temperature beyond of $45^{\circ} \mathrm{C}$.

3.2.6. Effect of the $\mathrm{H}_{2} \mathrm{O}_{2}$. Hydrogen peroxide concentration is an important parameter for the degradation of the pollutants in the heterogeneous photocatalysis. The effect of electron acceptors such as $\mathrm{H}_{2} \mathrm{O}_{2}$ on photodegradation efficiency is shown in Figure 8. From Figure 8 , it is observed that due to increasing of $\mathrm{H}_{2} \mathrm{O}_{2}$ from 33 to $66 \mathrm{mM}$, an increase in the degradation rate was resulted and the degradation efficiency was decreased beyond $66 \mathrm{mM} \mathrm{H}_{2} \mathrm{O}_{2}$. The enhanced degradation of PAP in the presence of $\mathrm{H}_{2} \mathrm{O}_{2}$ could be due to the trapping of electrons by hydrogen peroxide, thereby reducing the recombination of $e_{\mathrm{CB}}^{-}-h_{\mathrm{VB}}^{+}$pairs and thus increasing the chances of formation of ${ }^{\bullet} \mathrm{O}_{2}{ }^{-}, \mathrm{HOO}^{\bullet-}$, and ${ }^{\circ} \mathrm{OH}^{-}$on the catalyst surface. Indeed, two opposing factors must be considered: (i) if large quantities of $\mathrm{H}_{2} \mathrm{O}_{2}$ are added to the solution, the fraction of light absorbed by the photodecomposition promoter, and consequently its photolysis rate, increases. So, more hydroxyl radicals are available for the pollutant degradation. (ii) $\mathrm{OH}$ radicals efficiently react with 


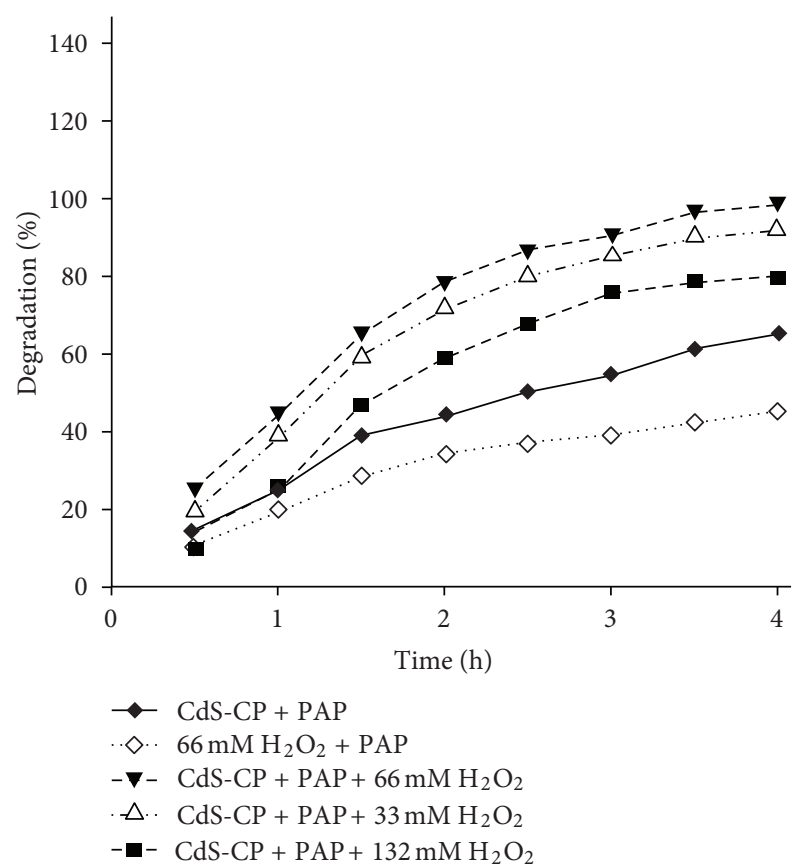

FIGURE 8: Effect of the electron acceptor on the photodegradation efficiency; $17.5 \mathrm{mg} \cdot \mathrm{L}^{-1}$ of catalyst; initial solution $\mathrm{pH}$, 5; initial PAP concentration, $10 \mathrm{ppm}$.

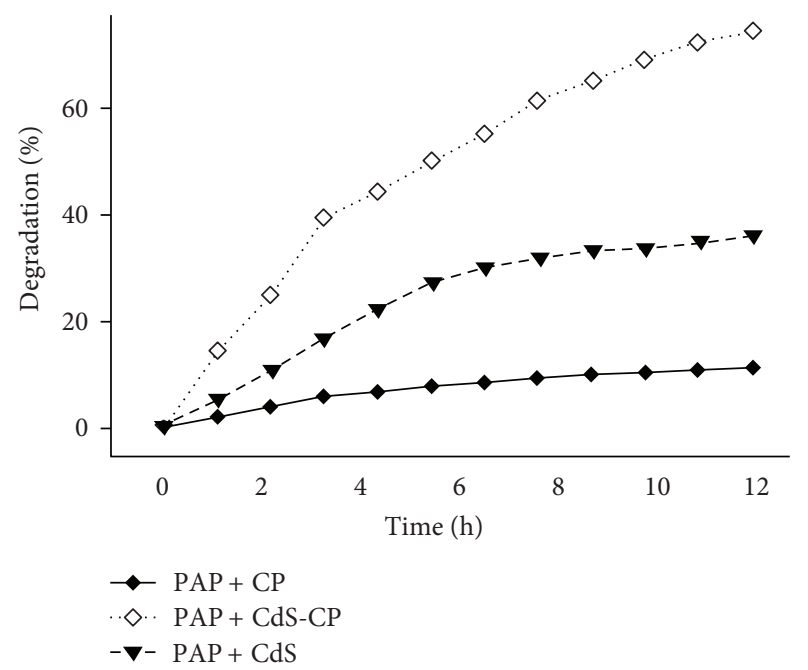

FIGURE 9: Effect of zeolite on the photocatalytic activity of CdS; $12.5 \mathrm{mg} \cdot \mathrm{L}^{-1}$ of catalyst; initial solution $\mathrm{pH}, 5$; initial PAP concentration, $10 \mathrm{ppm}$.

hydrogen peroxide $\left({ }^{\bullet} \mathrm{OH}+\mathrm{H}_{2} \mathrm{O}_{2} \rightarrow \mathrm{HO}_{2}^{\bullet}+\mathrm{H}_{2} \mathrm{O}\right.$ ), so that $\mathrm{H}_{2} \mathrm{O}_{2}$ in excess contributes to the $\mathrm{OH}^{-}$scavenging capacity and reduces the efficiency of pollutant degradation [47].

3.2.7. Effect of Zeolite. The amount of CdS loaded into zeolite measured by atomic absorption spectroscopy (by determination of $\mathrm{Cd}^{2+}$ ) was found to be $0.986 \mathrm{mmole}$ CdS/g CdS-CP. To determine whether the degradation of PAP by CdS takes place

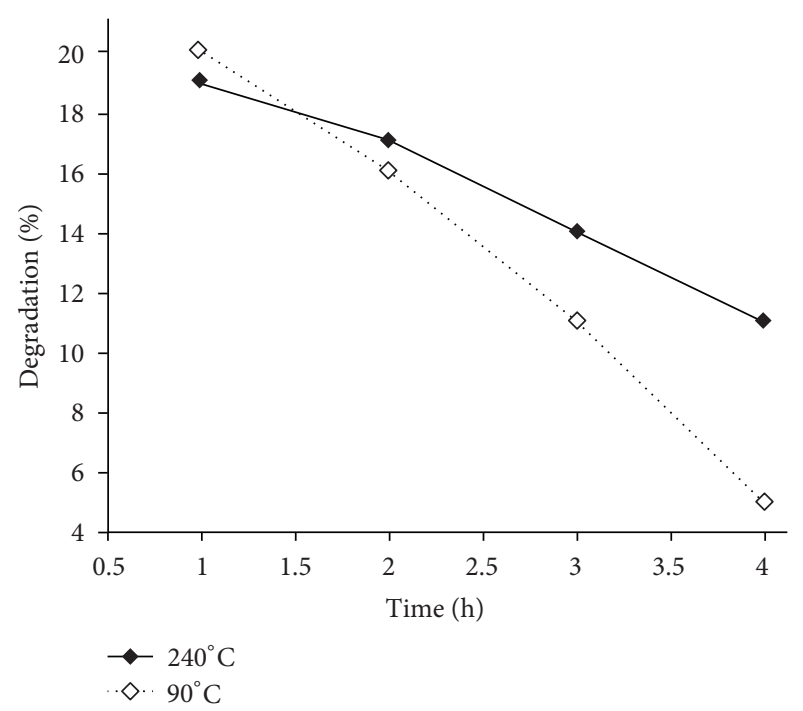

FIgURE 10: Effect of drying temperatures of 100 and $240^{\circ} \mathrm{C}$ on the reproducibility of the catalyst for PAP degradation in time interval of $90 \mathrm{~min} ; 17.5 \mathrm{mg} \cdot \mathrm{L}^{-1}$ of catalyst; initial solution $\mathrm{pH}$, 5; initial PAP concentration, $10 \mathrm{ppm}$.

or not, the catalytic activity of $2.4 \mathrm{mg} \mathrm{CdS} / \mathrm{L}$ (proportional to $17.5 \mathrm{mg} \mathrm{CdS}-\mathrm{CP} / \mathrm{L}$ ) was measured under the same abovementioned experimental conditions. No remarkable activity was noticed due to the presence of CdS as shown in Figure 9. The role of the zeolite might be correlated with the adsorption process, in the sense of high surface area and the decrease of particle size [37]. In our idea, in the absence of zeolite, CdS particles tend to aggregate which causes a decrease in the active surface sites. But in the case of CdS-incorporated zeolite, regarding to a small and definite pore size of zeolite, there are small particles of CdS in the zeolite that increase the available active sites of catalyst [48]. This, in turn, causes an increase in photodegradation efficiency. Catalytic efficiency of the zeolite CP towards PAP degradation was studied at above-mentioned conditions and the obtained results showed no considerable degradation efficiency. These results also show that the responsible active centers for PAP degradation are CdS particles loaded into zeolite.

3.2.8. Recovery Experiments. The possibility of reusing the photocatalyst was examined to see the cost effectiveness of the method. The catalyst was used in four consecutive experiments by using fresh dye solution at experimental conditions (10 ppm PAP concentration, $\mathrm{pH} 5,25^{\circ} \mathrm{C}, 17.5 \mathrm{mg} \cdot \mathrm{L}^{-1}$ catalyst for $90 \mathrm{~min}$ ). Between each experiment, the catalyst was removed by filtration and then washed with water several times and dried at 90 and $240^{\circ} \mathrm{C}$ for $90 \mathrm{~min}$. As seen from Figure 10 , the catalyst retained 94,74 , and $53 \%$ (in the case of $240^{\circ} \mathrm{C}$ ) and 80,51 , and $22 \%$ (in the case of $90^{\circ} \mathrm{C}$ ) of its initial activity during the second to fourth runs, respectively. A small and gradual decrease in the activity of catalysts was observed at the first two cycles. But, decreasing in the activity was seen intense after the first and fourth cycles for $90^{\circ} \mathrm{C}$ drying temperature case. Decreasing in the activity was not 


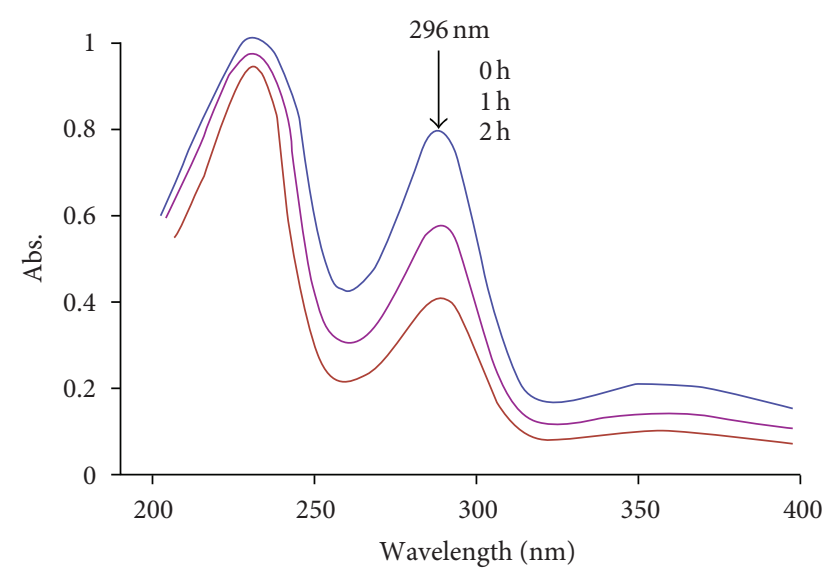

FIGURE 11: Decreased absorption spectra of PAP (10 ppm PAP solution, $\mathrm{pH}=7)$ in the presence of CdS-CP photocatalyst $\left(17.5 \mathrm{mg} \cdot \mathrm{L}^{-1}\right)$ in time interval of $2 \mathrm{~h}$.

considerable for $240^{\circ} \mathrm{C}$ drying temperature case. The decrease in the activity of the used catalyst must reflect the presence of some adventitious degradation products adsorbed in the zeolite, causing the partial blockage of the pore system or cover the zeolite surface. Preliminary thermal reactivation trials at $240^{\circ} \mathrm{C}$ did lead to an appreciable degradation of CdS$\mathrm{CP}$ photocatalyst as evidenced visually by the color change. Our results show a good agreement with the literature [48, 49].

3.2.9. UV-Vis Studies. Figure 11 shows the degradation of PAP (10 ppm) under the irradiation time interval of 2 hours and in the presence of CdS-CP catalyst $\left(17.5 \mathrm{mg} \cdot \mathrm{L}^{-1}, \mathrm{pH}\right.$ $=5)$. The decrease in the absorption spectra and therefore absorbance of samples at $\lambda_{\max }$ is indicated by degradation of PAP in the applied conditions. As a consequence, the decrease in the samples absorbance due to decrease of the pollutant concentration is recorded for measurement of degradation rate in the all above-mentioned parameters. Since there are no additional peaks appearing in the UV-Vis spectra, it is concluded that the pollutant is completely degraded. According to UV-Vis spectra, we suggest that the products of the degradation process are $\mathrm{H}_{2} \mathrm{O}, \mathrm{CO}_{2}$, and so forth. The proposed mechanism for the dye degradation using photocatalyst (PC) was suggested as follows:

$$
\begin{gathered}
\mathrm{PC}+h v \longrightarrow h_{\mathrm{vb}}^{+}+e_{\mathrm{cb}}^{-} \\
\mathrm{OH}^{-}+h_{\mathrm{vb}}^{+} \longrightarrow{ }^{\bullet} \mathrm{OH} \\
\mathrm{H}_{2} \mathrm{O}+h_{\mathrm{vb}}^{+} \longrightarrow{ }^{\bullet} \mathrm{OH}+\mathrm{H}^{+} \\
\mathrm{O}_{2}+e_{\mathrm{cb}}^{-} \longrightarrow \mathrm{O}_{2}^{-\bullet} \\
\mathrm{O}_{2}{ }^{-\bullet}+e_{\mathrm{cb}}^{-}+2 \mathrm{H}^{+} \longrightarrow \mathrm{H}_{2} \mathrm{O}_{2} \\
2 \mathrm{O}_{2}{ }^{-\bullet}+2 \mathrm{H}^{+} \longrightarrow \mathrm{O}_{2}+\mathrm{H}_{2} \mathrm{O}_{2} \\
\mathrm{H}_{2} \mathrm{O}_{2}+e_{\mathrm{cb}}^{-} \longrightarrow \mathrm{OH}^{-}+{ }^{\bullet} \mathrm{OH}
\end{gathered}
$$

$$
\begin{aligned}
& \mathrm{PAP}+h_{\mathrm{vb}}^{+} \longrightarrow \mathrm{PAP}^{+\bullet} \longrightarrow \text { Final products } \\
& \mathrm{PAP}+{ }^{\bullet} \mathrm{OH} \longrightarrow \mathrm{PAP}^{\bullet} \longrightarrow \text { Final products }
\end{aligned}
$$

\section{Conclusion}

The PAP pollutant can be more efficiently degraded by CdS-incorporated zeolite clinoptilolite in the presence of $\mathrm{UV}$ radiation. It is important to choose the optimum degradation parameters for increasing the degradation rate. The optimal operation parameters were found as follows: $\mathrm{pH} 5,17.5 \mathrm{mg} \cdot \mathrm{L}^{-1}$ of catalyst loading, and $10 \mathrm{ppm}$ of PAP concentration and the obtained results obeyed first-order kinetics. The catalyst can be reused for the dye degradation with slightly loss in its efficiency. Zeolite bed shows an important role in the degradation process so that $\mathrm{CdS}$ out of zeolite framework and also zeolite CP did not show significant degradation efficiency. The results demonstrate that the active centers are $\mathrm{CdS}$ in the zeolite structure. A very small amount of used photocatalyst $\left(17.5 \mathrm{mg} \cdot \mathrm{L}^{-1}\right)$ is important advantage of the proposed method, which save an photocatalyst and photons due to reducible scattering and finally less contamination of the environment.

\section{References}

[1] I. A. Shiklomanov and J. C. Roda, World Water Resources at the Beginning of the Twenty-First Century, International Hydrogen Series, Cambridge University Press, Cambridge, UK, 2003.

[2] O. Legrini, E. Oliveros, and A. M. Braun, "Photochemical processes for water treatment," Chemical Reviews, vol. 93, no. 2, pp. 671-698, 1993.

[3] M. A. Brown and S. C. DeVito, "Predicting azo dye toxicity," Critical Reviews in Environmental Science and Technology, vol. 23, no. 3, pp. 249-324, 1993.

[4] S. Mitchell, Kirk-Othmer Encyclopaedia of Chemical Technology, vol. 2, Wiley-Interscience, New York, NY, USA, 4th edition, 1992.

[5] K. Venkatraman, The Chemistry of Synthetic Dyes, vol. 1, Academic Press, New York, NY, USA, 1952.

[6] F. Bernheim and M. L. C. Bernheim, "The effect of various compounds on urea formation by rat liver slices," The Journal of Biological Chemistry, vol. 178, pp. 903-909, 1994.

[7] S. Andreescu, A. Avramescu, C. Bala, V. Magearu, and J. L. Marty, "Detection of organophosphorus insecticides with immobilized acetylcholinesterase-comparative study of two enzyme sensors," Analytical and Bioanalytical Chemistry, vol. 374, no. 1, pp. 39-45, 2002.

[8] H. Filik, I. Şener, S. D. Cekiç, E. Kiliç, and R. Apak, "Spectrophotometric determination of paracetamol in urine with tetrahydroxycalix[4]arene as a coupling reagent and preconcentration with Triton X-114 using cloud point extraction," Chemical and Pharmaceutical Bulletin, vol. 54, no. 6, pp. 891-896, 2006.

[9] Minnesota Ground Water Association, vol. 19, 2000, http:// www.mgwa.org/.

[10] N. Serpone and E. E. Pelizzetti, Photocatalysis, Fundamentals and Applications, Wiley, New York, NY, USA, 1989.

[11] M. H. Habibi and E. Askari, "Photocatalytic degradation of an azo textile dye with manganese-doped $\mathrm{ZnO}$ nanoparticles 
coated on glass," Iranian Journal of Catalysis, vol. 1, pp. 41-44, 2011.

[12] H. Faghihian and A. Bahranifard, "Application of $\mathrm{TiO}_{2}$-zeolite as photocatalyst for photodegradation of some organic pollutants," Iranian Journal of Catalysis, vol. 1, pp. 45-50, 2011.

[13] A. Nezamzadeh-Ejhieh and M. Khorsandi, "A comparison between the heterogeneous photodecolorization of an azo dye using Ni/P zeolite and NiS/P zeolite catalysts," Iranian Journal of Catalysis, vol. 1, no. 2, pp. 99-104, 2011.

[14] J. Gunlazuardi and W. A. Lindu, "Photocatalytic degradation of pentachlorophenol in aqueous solution employing immobilized $\mathrm{TiO}_{2}$ supported on titanium metal," Journal of Photochemistry and Photobiology A, vol. 173, no. 1, pp. 51-55, 2005.

[15] A. N. Ökte and Ö. Yilmaz, "Characteristics of lanthanum loaded $\mathrm{TiO}_{2}-\mathrm{ZSM}-5$ photocatalysts: decolorization and degradation processes of methyl orange," Applied Catalysis A, vol. 354, no. 1-2, pp. 132-142, 2009.

[16] D. W. Breck, , Zeolite Molecular Sieves, Wiley, New York, NY, USA, 1974.

[17] S. Sohrabnezhad and A. Pourahmad, "Comparison absorption of new methylene blue dye in zeolite and nanocrystal zeolite," Desalination, vol. 256, no. 1-3, pp. 84-89, 2010.

[18] I. Othman, R. M. Mohamed, I. A. Ibrahim, and M. M. Mohamed, "Synthesis and modification of ZSM-5 with manganese and lanthanum and their effects on decolorization of indigo carmine dye," Applied Catalysis A, vol. 299, no. 1-2, pp. 95-102, 2006.

[19] G. Gottardi and E. Galli, Natural Zeolites, Springer, New York, NY, USA, 1985.

[20] A. Nezamzadeh-Ejhieh and S. Moeinirad, "Heterogeneous photocatalytic degradation of furfural using NiS-clinoptilolite zeolite," Desalination, vol. 273, no. 2-3, pp. 248-257, 2011.

[21] W. Chengyu, S. Huamei, T. Ying, Y. Tongsuo, and Z. Guowu, "Properties and morphology of $\mathrm{CdS}$ compounded $\mathrm{TiO}_{2}$ visiblelight photocatalytic nanofilms coated on glass surface," Separation and Purification Technology, vol. 32, no. 1-3, pp. 357-362, 2003.

[22] H. Khallaf, I. O. Oladeji, and L. Chow, "Optimization of chemical bath deposited CdS thin films using nitrilotriacetic acid as a complexing agent," Thin Solid Films, vol. 516, no. 18, pp. 5967-5973, 2008.

[23] J. C. Tristão, F. Magalhães, P. Corio, and M. T. C. Sansiviero, "Electronic characterization and photocatalytic properties of $\mathrm{CdS} / \mathrm{TiO}_{2}$ semiconductor composite," Journal of Photochemistry and Photobiology A, vol. 181, no. 2-3, pp. 152-157, 2006.

[24] T. Kida, G. Guan, and A. Yoshida, " $\mathrm{LaMnO}_{3} / \mathrm{CdS}$ nanocomposite: a new photocatalyst for hydrogen production from water under visible light irradiation," Chemical Physics Letters, vol. 371, no. 5-6, pp. 563-567, 2003.

[25] R. Ochoa-Landín, M. Flores-Acosta, R. Ramírez-Bon, H. Arizpe-Chávez, M. Sotelo-Lerma, and F. F. Castillón-Barraza, "Characterization of Cds clusters in zeolite-A grown in alkaline solution," Journal of Physics and Chemistry of Solids, vol. 64, no. 11, pp. 2245-2251, 2003.

[26] M. Sathish, B. Viswanathan, and R. P. Viswanath, "Alternate synthetic strategy for the preparation of CdS nanoparticles and its exploitation for water splitting," International Journal of Hydrogen Energy, vol. 31, no. 7, pp. 891-898, 2006.

[27] H. Khallaf, I. O. Oladeji, and L. Chow, "Optimization of chemical bath deposited CdS thin films using nitrilotriacetic acid as a complexing agent," Thin Solid Films, vol. 516, no. 18, pp. 5967-5973, 2008.
[28] J. C. Tristão, F. Magalhães, P. Corio, and M. T. C. Sansiviero, "Electronic characterization and photocatalytic properties of $\mathrm{CdS} / \mathrm{TiO}_{2}$ semiconductor composite," Journal of Photochemistry and Photobiology A, vol. 181, no. 2-3, pp. 152-157, 2006.

[29] T. Kida, G. Guan, and A. Yoshida, " $\mathrm{LaMnO}_{3} / \mathrm{CdS}$ nanocomposite: a new photocatalyst for hydrogen production from water under visible light irradiation," Chemical Physics Letters, vol. 371, no. 5-6, pp. 563-567, 2003.

[30] M. Sathish, B. Viswanathan, and R. P. Viswanath, "Alternate synthetic strategy for the preparation of CdS nanoparticles and its exploitation for water splitting," International Journal of Hydrogen Energy, vol. 31, no. 7, pp. 891-898, 2006.

[31] E. M. Flanigen, H. Khatami, and H. A. Szymanski, Molecular Sieve Zeolite I, Academic Press, New York, NY, USA, 1971.

[32] V. Sundaramurthy and N. Lingappan, "Isomorphic substitution of boron in ZSM-5 type zeolites using TBP as template," Journal of Molecular Catalysis A, vol. 160, no. 2, pp. 367-375, 2000.

[33] Z. Sobalik, J. Dedecek, I. Ikonnikov, and B. Wichterlova, "Monitoring of skeletal T-O-T vibrations of metal ion exchanged zeolites: an attempt at quantitative evaluation," Microporous and Mesoporous Materials, vol. 25, pp. 225-228, 1998.

[34] A. Auroux, G. Goudurier, R. Shannon, and J. C. Vedrine, in Proceedings of the AFCAT Meeting, S. Portyka and M. Lindhemer, Eds., vol. 16, p. 68, Montpellier, France, 1987.

[35] M. W. Kasture, P. N. Joshi, H. S. Soni, V. V. Joshi, A. L. Choudhari, and V. P. Shiralkar, "Sorption properties of the natural, $\mathrm{K}$ and partially deammoniated (H/NH4) forms of clinoptilolite," Adsorption Science and Technology, vol. 16, no. 2, pp. 135-151, 1998.

[36] D. A. Skoog and J. J. Leary, Principles of Instrumental Analysis, Sannders College, New York, NY, USA, 4th edition, 1992.

[37] Z. M. El-Bahy, M. M. Mohamed, F. I. Zidan, and M. S. Thabet, "Photo-degradation of acid green dye over Co-ZSM-5 catalysts prepared by incipient wetness impregnation technique," Journal of Hazardous Materials, vol. 153, no. 1-2, pp. 364-371, 2008.

[38] M. Qamar and M. Muneer, "A comparative photocatalytic activity of titanium dioxide and zinc oxide by investigating the degradation of vanillin," Desalination, vol. 249, no. 2, pp. 535-540, 2009.

[39] A. N. Ejhieh and M. Khorsandi, "Photodecolorization of Eriochrome Black T using NiS-P zeolite as a heterogeneous catalyst," Journal of Hazardous Materials, vol. 176, no. 1-3, pp. 629-637, 2010.

[40] A. Nezamzadeh-Ejhieh and M. Khorsandi, "Heterogeneous photodecolorization of Eriochrome Black T using Ni/P zeolite catalyst," Desalination, vol. 262, no. 1-3, pp. 79-85, 2010.

[41] J. Grzechulska and A. W. Morawski, "Photocatalytic decomposition of azo-dye acid black 1 in water over modified titanium dioxide," Applied Catalysis B, vol. 36, no. 1, pp. 45-51, 2002.

[42] Y. Li, Y. Lu, and X. Zhu, "Photo-Fenton discoloration of the azo dye X-3B over pillared bentonites containing iron," Journal of Hazardous Materials, vol. 132, no. 2-3, pp. 196-201, 2006.

[43] A. Aleboyeh, Y. Moussa, and H. Aleboyeh, "The effect of operational parameters on $\mathrm{UV} / \mathrm{H}_{2} \mathrm{O}_{2}$ decolourisation of Acid Blue 74," Dyes and Pigments, vol. 66, no. 2, pp. 129-134, 2005.

[44] J. Saien and A. R. Soleymani, "Degradation and mineralization of Direct Blue 71 in a circulating upflow reactor by $\mathrm{UV} / \mathrm{TiO}_{2}$ process and employing a new method in kinetic study," Journal of Hazardous Materials, vol. 144, no. 1-2, pp. 506-512, 2007.

[45] C. Catrinescu, C. Teodosiu, M. Macoveanu, J. Miehe-Brendlé, and R. Le Dred, "Catalytic wet peroxide oxidation of phenol 
over Fe-exchanged pillared beidellite," Water Research, vol. 37, no. 5, pp. 1154-1160, 2003.

[46] A. K. Gupta, A. Pal, and C. Sahoo, "Photocatalytic degradation of a mixture of Crystal Violet (Basic Violet 3) and Methyl Red dye in aqueous suspensions using $\mathrm{Ag}^{+}$doped $\mathrm{TiO}_{2}$," Dyes and Pigments, vol. 69, no. 3, pp. 224-232, 2006.

[47] A. Aleboyeh, H. Aleboyeh, and Y. Moussa, "'Critical' effect of hydrogen peroxide in photochemical oxidative decolorization of dyes: acid Orange 8, Acid Blue 74 and Methyl Orange," Dyes and Pigments, vol. 57, no. 1, pp. 67-75, 2003.

[48] M. Alvaro, E. Carbonell, M. Esplá, and H. Garcia, "Iron phthalocyanine supported on silica or encapsulated inside zeolite $\mathrm{Y}$ as solid photocatalysts for the degradation of phenols and sulfur heterocycles," Applied Catalysis B, vol. 57, no. 1, pp. 37-42, 2005.

[49] H. R. Pouretedal, A. Norozi, M. H. Keshavarz, and A. Semnani, "Nanoparticles of zinc sulfide doped with manganese, nickel and copper as nanophotocatalyst in the degradation of organic dyes," Journal of Hazardous Materials, vol. 162, no. 2-3, pp. 674-681, 2009. 

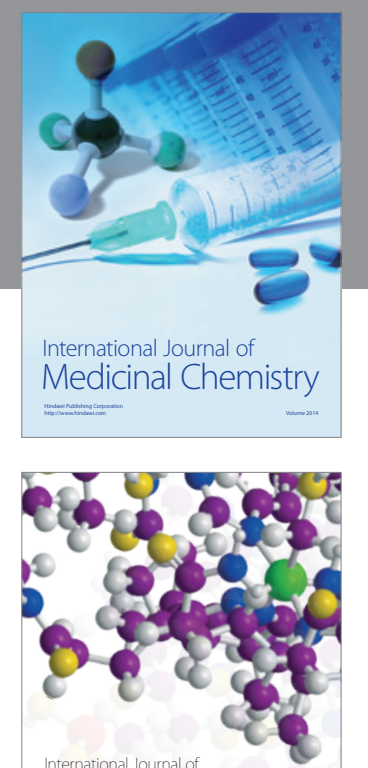

\section{Carbohydrate} Chemistry

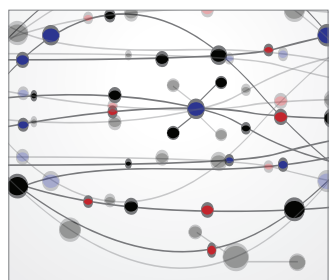

The Scientific World Journal
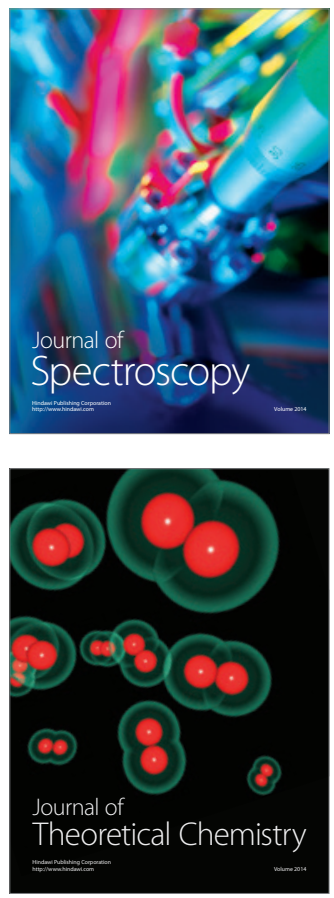
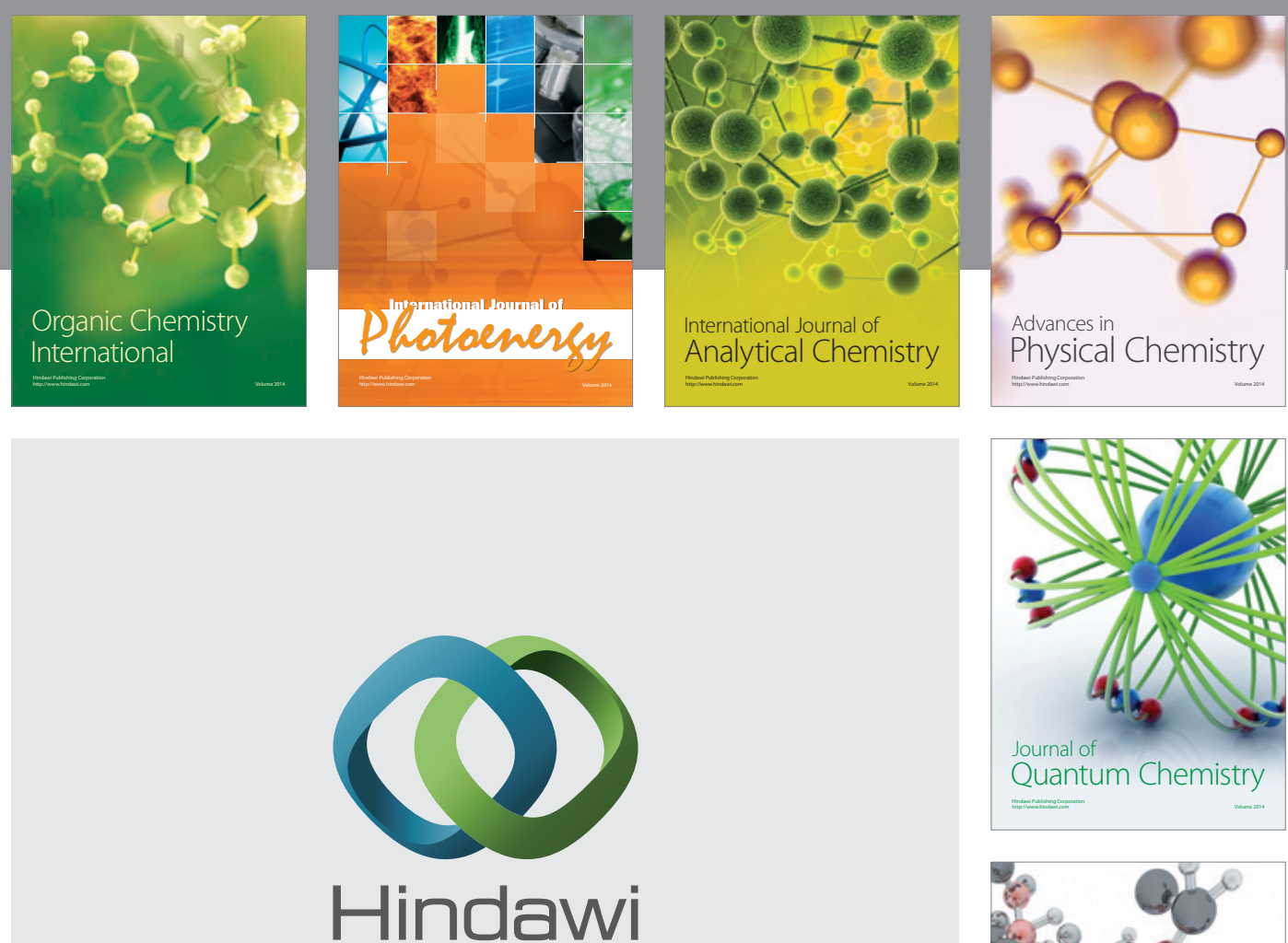

Submit your manuscripts at

http://www.hindawi.com

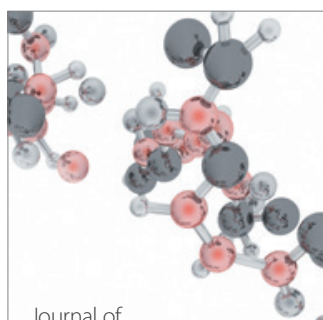

Analytical Methods

in Chemistry

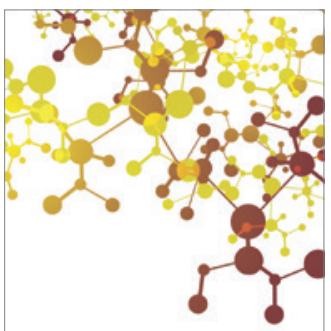

Journal of

Applied Chemistry

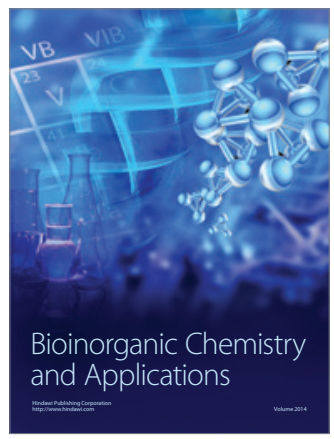

Inorganic Chemistry
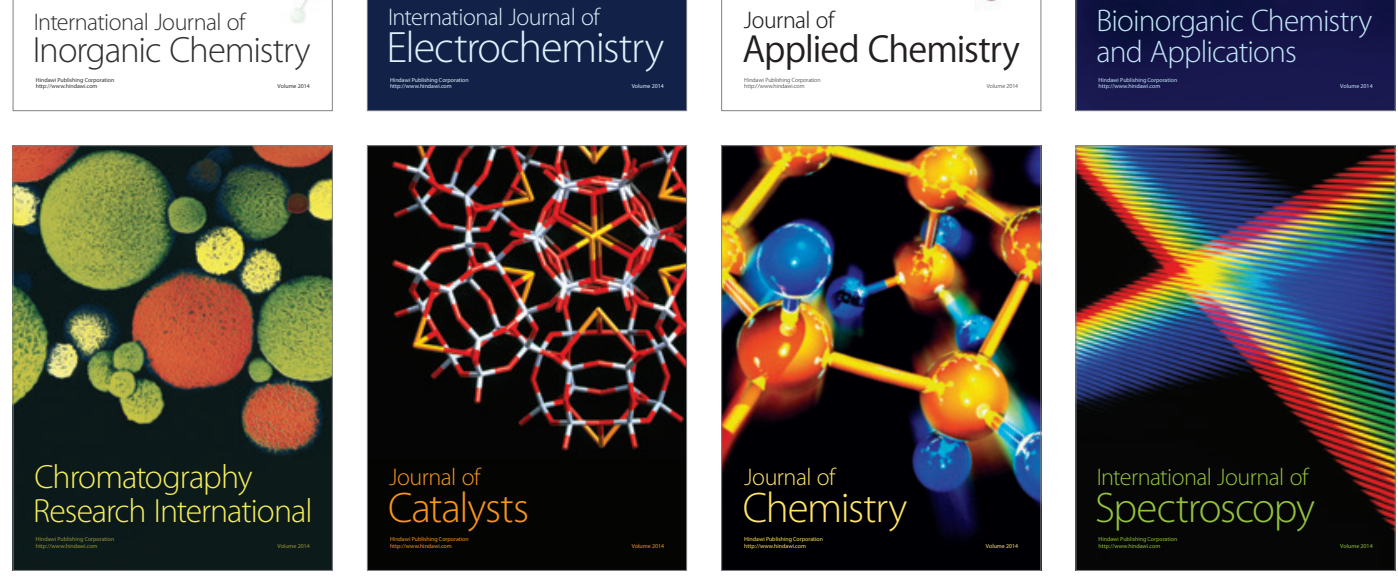